\title{
Dynamic hip kinematics during recreational classical ballet and hula dance after total hip arthroplasty: two case reports
}

\author{
Keisuke Komiyama ${ }^{1}$, Satoshi Hamai ${ }^{*}$ (D), Daisuke Hara ${ }^{1}$, Satoru Ikebe ${ }^{3}$, Yifeng Wang ${ }^{2}$, Hirotaka Gondo², \\ Hidehiko Higaki ${ }^{2}$ and Yasuharu Nakashima'
}

\begin{abstract}
Background: The in vivo assessment of the three-dimensional kinematics of the hip during dance activities in patients after total hip arthroplasty has not been previously reported. We evaluated the replaced hip kinematics during recreational classical ballet and hula dance using radiographic-based image-matching techniques.

Case presentation: A 58-year-old Japanese woman (patient 1; height, $157 \mathrm{~cm}$; weight, $74.5 \mathrm{~kg}$ ) and a 73 -year-old Japanese woman (patient 2; height, $153 \mathrm{~cm}$; weight, $48 \mathrm{~kg}$ ) were still doing classical ballet and hula dance, respectively, after primary total hip arthroplasty. For ballet, there were gradual three-dimensional hip movements with $48^{\circ}$ flexion, $36^{\circ}$ abduction, and $49^{\circ}$ external rotation in développé and $34^{\circ}$ flexion, $29^{\circ}$ abduction, and $43^{\circ}$ external rotation in plié. For hula, there were small three-dimensional hip movements with $31^{\circ}$ flexion, $15^{\circ}$ adduction, and $11^{\circ}$ external rotation in kao and $17^{\circ}$ flexion, $11^{\circ}$ adduction, and $11^{\circ}$ external rotation in kaholo. No liner-to-neck contact was found in any dance activities.

Conclusion: Both classical ballet and hula dance produced complex ranges of hip movements and activitydependent kinematics. These kinematic data could be useful for recommending each patient with total hip arthroplasty to continue recreational dance activities.
\end{abstract}

Keywords: Hula, Ballet, Dance, Total hip arthroplasty, Kinematics, Image-matching

\section{Background}

Total hip arthroplasty (THA) provides pain relief, deformity correction and restored function, and promotes good long-term outcomes [1-3]. The clinical success of THA allows some patients to participate in sports activities and expectations of returning to sports activities have become more important to patients than ever before [4-6]. Participation in physical activities has positive effects on patients, such as improved bone quality, muscle strength, flexibility, and implant fixation [7-9].

Healy et al. reported that a survey conducted in 2005 revealed that members of The Hip Society allowed square dancing after THA [4]. Ollivier et al. reported that 93 patients out of 571 patients (16.3\%) enjoyed

\footnotetext{
* Correspondence: hamachan@ortho.med.kyushu-u.ac.jp

${ }^{1}$ Department of Orthopedic Surgery, Graduate School of Medical Sciences,

Kyushu University, 3-1-1 Maidashi, Higashi-ku, Fukuoka 812-8582, Japan

Full list of author information is available at the end of the article
}

dancing activities after THA [5]. However, concerns exist about whether dance can be performed in a safe manner after THA. To the best of our knowledge, no previous report is available that studies the in vivo three-dimensional kinematics of dance after THA. Image-matching techniques have provided reliable information on three-dimensional hip joint range of motion (ROM) during daily and sports activities [10-15]. Based on the kinematic data, patients after THA could be instructed regarding risks associated with specific postures [12].

The purpose of this study was to measure dynamic hip kinematics during classical ballet and Hawaiian dance after THA using image-matching techniques. The following question was addressed: What values of flexion/extension, adduction/abduction, and axial rotation are produced at the hip joint?

(C) The Author(s). 2019 Open Access This article is distributed under the terms of the Creative Commons Attribution 4.0 International License (http://creativecommons.org/licenses/by/4.0/), which permits unrestricted use, distribution, and reproduction in any medium, provided you give appropriate credit to the original author(s) and the source, provide a link to the Creative Commons license, and indicate if changes were made. The Creative Commons Public Domain Dedication waiver (http://creativecommons.org/publicdomain/zero/1.0/) applies to the data made available in this article, unless otherwise stated. 


\section{Case presentation}

A 58-year-old Japanese woman (patient 1; height, 157 $\mathrm{cm}$; weight, $74.5 \mathrm{~kg}$; body mass index, $30.2 \mathrm{~kg} / \mathrm{m}^{2}$ ) and a 73-year-old Japanese woman (patient 2; height, $153 \mathrm{~cm}$; weight, $48 \mathrm{~kg}$; body mass index, $20.5 \mathrm{~kg} / \mathrm{m}^{2}$ ) were still doing classical ballet and hula dance, respectively, after primary THA for osteoarthritis (OA) due to developmental dysplasia of the hip. They received medication and rehabilitation prior to surgery for 2 and 10 years, respectively. Patient 1 could not do classical ballet before surgery, and returned to doing classical ballet recreationally with satisfaction after surgery. Patient 1's preoperative Oxford Hip Score (OHS) $[16,17]$ and University of California-Los Angeles (UCLA) activity scale score $[17,18]$ were 4 and 1 , respectively. Patient 2 did hula dance with difficulty due to right coxalgia, and enjoyed hula dancing after surgery. Patient 2's preoperative OHS and UCLA score were 4 and 2, respectively. The occupation of both patients was homemaker. The OHS, the UCLA score, and the Harris Hip Score (HHS) [19] in patient 1 were 48,8 , and 100 , respectively, at 4 years of follow-up after surgery. The OHS, the UCLA score, and the HHS in patient 2 were 48, 5, and 80 , respectively, at 6 years of follow-up after surgery. The OHS and UCLA score are validated, reliable, and self-reported metric assessments for patients with hip OA [16-18]. The OHS assesses the pain and function of the hip during daily activities, while the UCLA score measures physical activity levels. Both patients provided written consent for this institutional review board-approved study and were willing to participate and enroll in the study.

A cementless hemispherical press fit cup, straight metaphyseal fit stem, alumina ceramic femoral heads (patient $1,32 \mathrm{~mm}$; patient $2,26 \mathrm{~mm}$ ), and highly crosslinked ultra-high molecular weight polyethylene liner with a $15^{\circ}$ elevated rim $\left(\mathrm{AMS}^{\circ}\right.$ and PerFix HA, Aeonian; Kyocera Medical, Osaka, Japan) were used [2, 3, 12]. All operations were performed using combined anteversion technique via a posterolateral approach [20,21].

The three-dimensional positions and orientations of the pelvis, acetabular cup, femur, and femoral stem during dance were determined using image-matching techniques [10]. The patients performed dance under continuous radiographic surveillance using a flat panel $\mathrm{X}$-ray detector (Ultimax-I, Toshiba, Tochigi, Japan): image area, $420 \mathrm{~mm} \times$ $420 \mathrm{~mm}$; resolution, $0.274 \mathrm{~mm} \times 0.274 \mathrm{~mm} /$ pixel; and frame

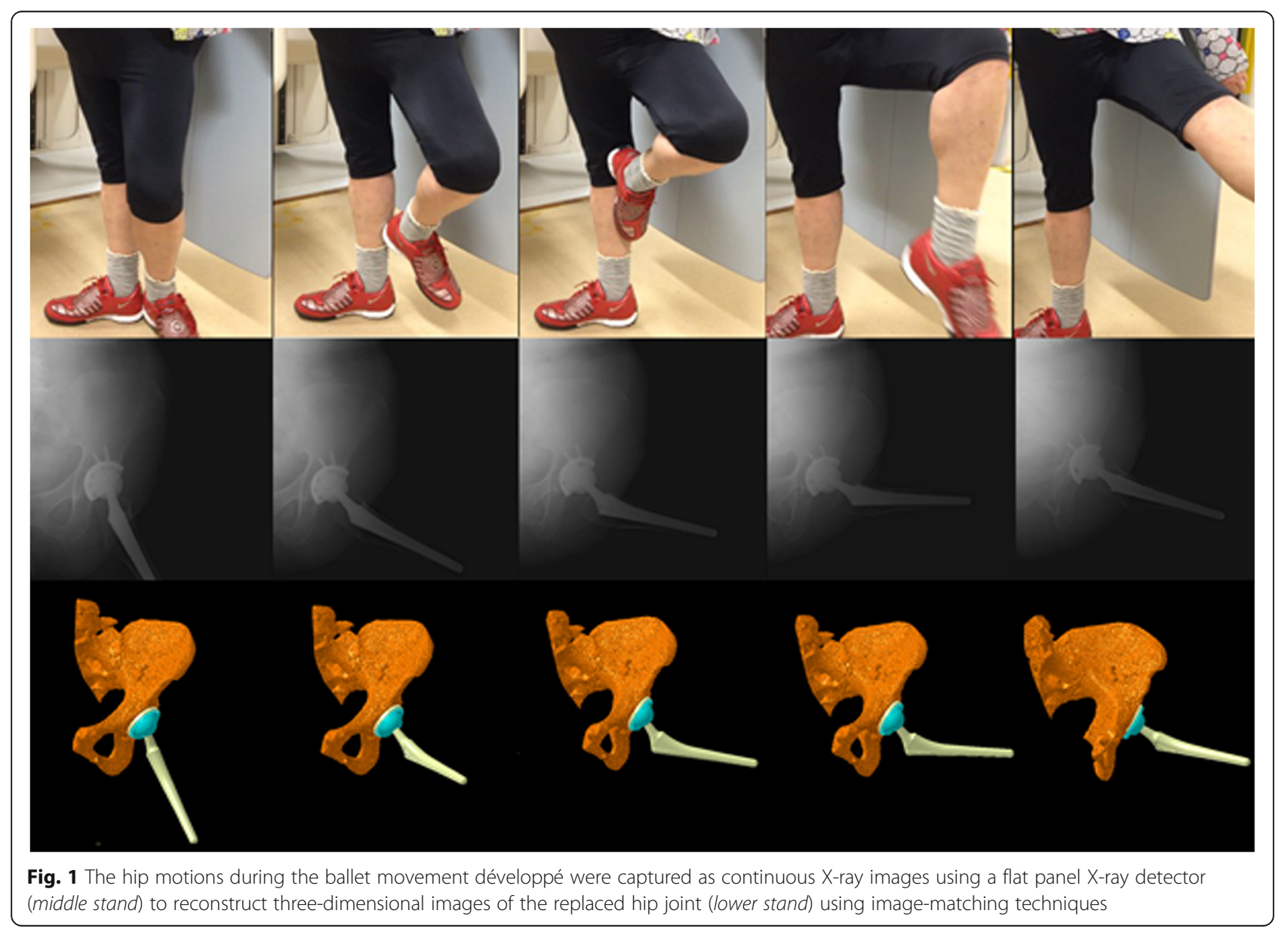


rate, 3.5 frames/second (Figs. 1, 2, 3, and 4). Each patient routinely underwent computed tomography (CT; Aquilion, Toshiba, Tochigi, Japan) with a $512 \times 512$ image matrix, $0.35 \times 0.35$ pixel dimensions, and $1-\mathrm{mm}$ slice thickness from the superior edge of the pelvis to just below the knee joint line. Anatomical coordinate systems of the pelvis and femur were embedded in each bone model derived from CT data according to our previous study [12]. Computer simulation was performed to generate virtual digitally reconstructed radiographs (DRRs), in which the light source and projected plane parameters were set to be identical to the actual radiographic imaging conditions. Each model silhouette was matched with the actual silhouette by translating and rotating the three-dimensional model to minimize the number of unmatched pixels between the silhouettes. The orientation of the femur relative to the pelvis: hip movements, was determined using the Cardan/Euler angle system in $x-y-z$ order (flexion/extension, adduction/abduction, internal/external rotation). Contact between the acetabular liner and the stem neck (liner-to-neck contact) was also evaluated using a computer-aided design (CAD) software program (CATIA V5; Dassault Systèmes). The maximum errors associated with tracking the position of the femur/stem relative to the pelvis/acetabular cup were $0.36 / 0.43 \mathrm{~mm}, 0.37 / 0.48 \mathrm{~mm}$, and $0.48^{\circ} / 0.52^{\circ}$, respectively, for in-plane translation, out-of-plane translation, and rotation, respectively [12].

The orientations of the acetabular cup and stem were measured using postoperative CT data. Cup inclination was measured as the angle of abduction using the inter-tear-drop line as the baseline (radiographic inclination). Cup anteversion was measured as the angle of anteversion in the sagittal plane (operative anteversion). Femoral anteversion was measured as the angle of anteversion between the prosthetic femoral neck and transe-epicondylar axis (TEA). The cup inclination, cup anteversion, and stem anteversion in patients 1 and 2 were: $40.1^{\circ}, 41.0^{\circ} ; 14.4^{\circ}, 25.9^{\circ}$; and $34.8^{\circ}, 21.8^{\circ}$, respectively.

\section{Classical ballet}

For the ballet movements of développé (Fig. 1) and plié (Fig. 2), there were gradual three-dimensional hip movements (Figs. 5 and 6). Développé produced $75.3^{\circ}$ of maximum femoral flexion with $27.8^{\circ}$ of posterior pelvic tilt (Fig. 5). Hip flexion peaked on the way of movement with $47.5^{\circ}$ of maximum flexion. The maximum hip abduction was $36.1^{\circ}$ with $49.3^{\circ}$ of hip external rotation. Plié produced

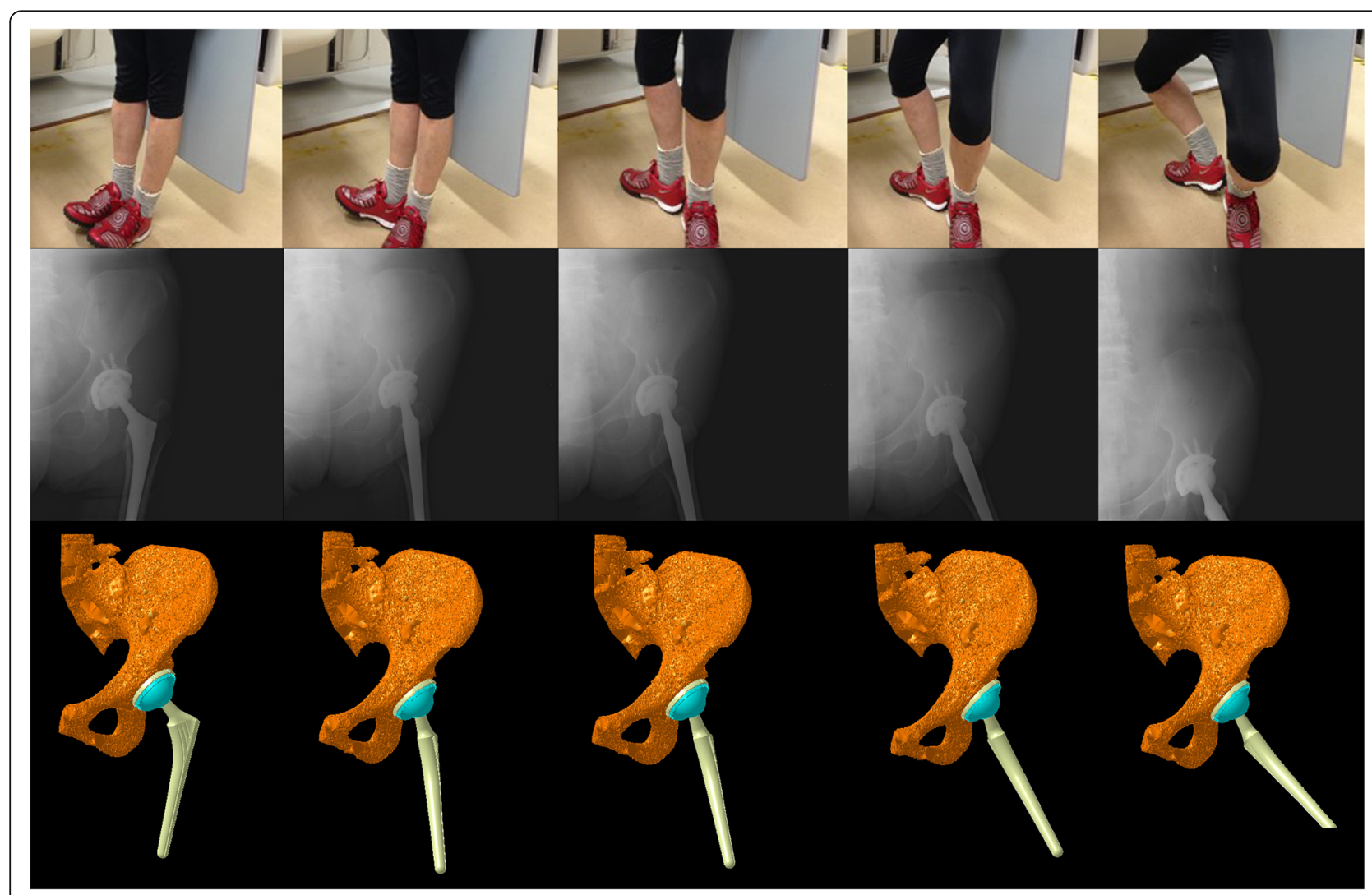

Fig. 2 The hip motions during the ballet movement plié were captured as continuous X-ray images using a flat panel X-ray detector (middle stand) to reconstruct three-dimensional images of the replaced hip joint (lower stand) using image-matching techniques 


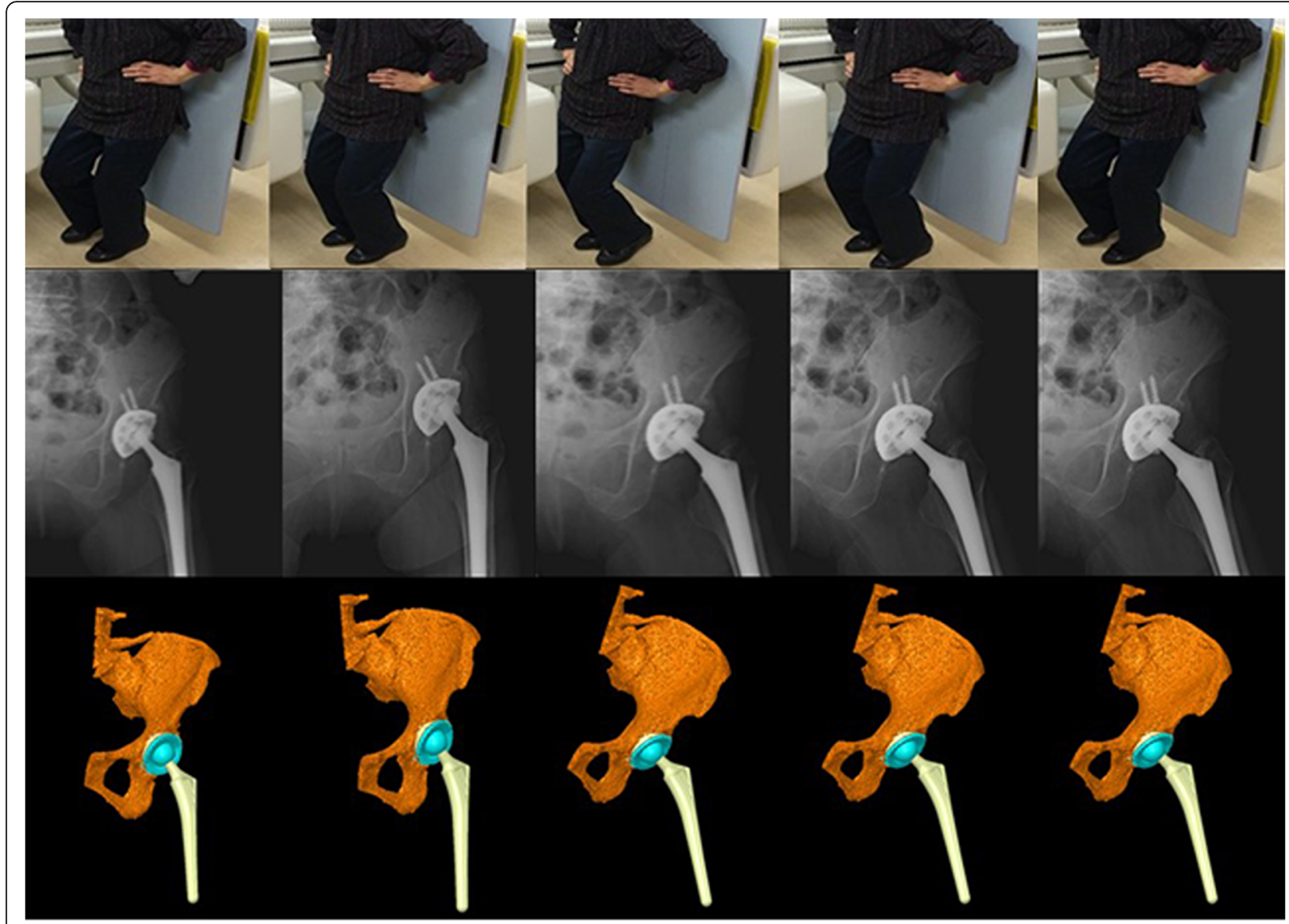

Fig. 3 The hip motions during the hula dance movement kao were captured as continuous X-ray images using a flat panel X-ray detector (middle stand) to reconstruct three-dimensional images of the replaced hip joint (lower stand) using image-matching techniques

$41.6^{\circ}$ of maximum femoral flexion with $10.7^{\circ}$ of posterior pelvic tilt in the sagittal plane (Fig. 6). Hip flexion peaked on the way of movement with $33.5^{\circ}$ of maximum flexion. The maximum hip abduction was $29.4^{\circ}$ with $43.3^{\circ}$ of hip external rotation. No liner-to-neck contact was found in either développé or plié.

\section{Hula dance}

In the hula dance movement called kao (Fig. 3), hip flexion/extension ranged from $4.6^{\circ}$ of flexion to $30.6^{\circ}$ of flexion with $15.1^{\circ}$ of maximum hip abduction and $11.1^{\circ}$ of maximum hip external rotation (Fig. 7). We observed $13.3^{\circ}$ of total amount of ipsilateral pelvic obliquity with $16.0^{\circ}$ and $15.6^{\circ}$ of total amount of posterior pelvic tilt and contralateral pelvic rotation, respectively. In the kaholo (Fig. 4), hip flexion/extension ranged from $7.9^{\circ}$ of flexion to $16.7^{\circ}$ of flexion with $11^{\circ}$ of maximum hip abduction and $10.7^{\circ}$ of maximum hip external rotation (Fig. 8). We observed $9.3^{\circ}$ of total amount of ipsilateral pelvic obliquity with $15.1^{\circ}$ and $0.8^{\circ}$ of total amount of posterior pelvic tilt and contralateral pelvic rotation, respectively. No liner-to-neck contact was found in either kao or kaholo.

\section{Discussion}

To the best of our knowledge, this is the first in vivo study to examine the dynamic kinematics of the hip joint during dance activities in patients after THA. In this analysis, classical ballet and hula dance produced complex ranges of hip movements and activity-dependent kinematics. For classical ballet, développé/plié produced approximately $48^{\circ} / 34^{\circ}$ of maximum hip flexion with $36^{\circ} /$ $29^{\circ}$ of maximum abduction and $49^{\circ} / 43^{\circ}$ of maximum external rotation. For hula dance, kao/kaholo produced approximately $31^{\circ} / 17^{\circ}$ of maximum flexion with $15^{\circ} / 11^{\circ}$ of maximum abduction and $11^{\circ} / 11^{\circ}$ of maximum external rotation. No liner-to-neck contact was found in any dance activities.

More than ever before, patients have high expectations in terms of functional outcomes and returning to sports after THA [4]. The present two cases could return to recreational classical ballet and Hula dance with satisfaction after THA. Although there is little information on the 


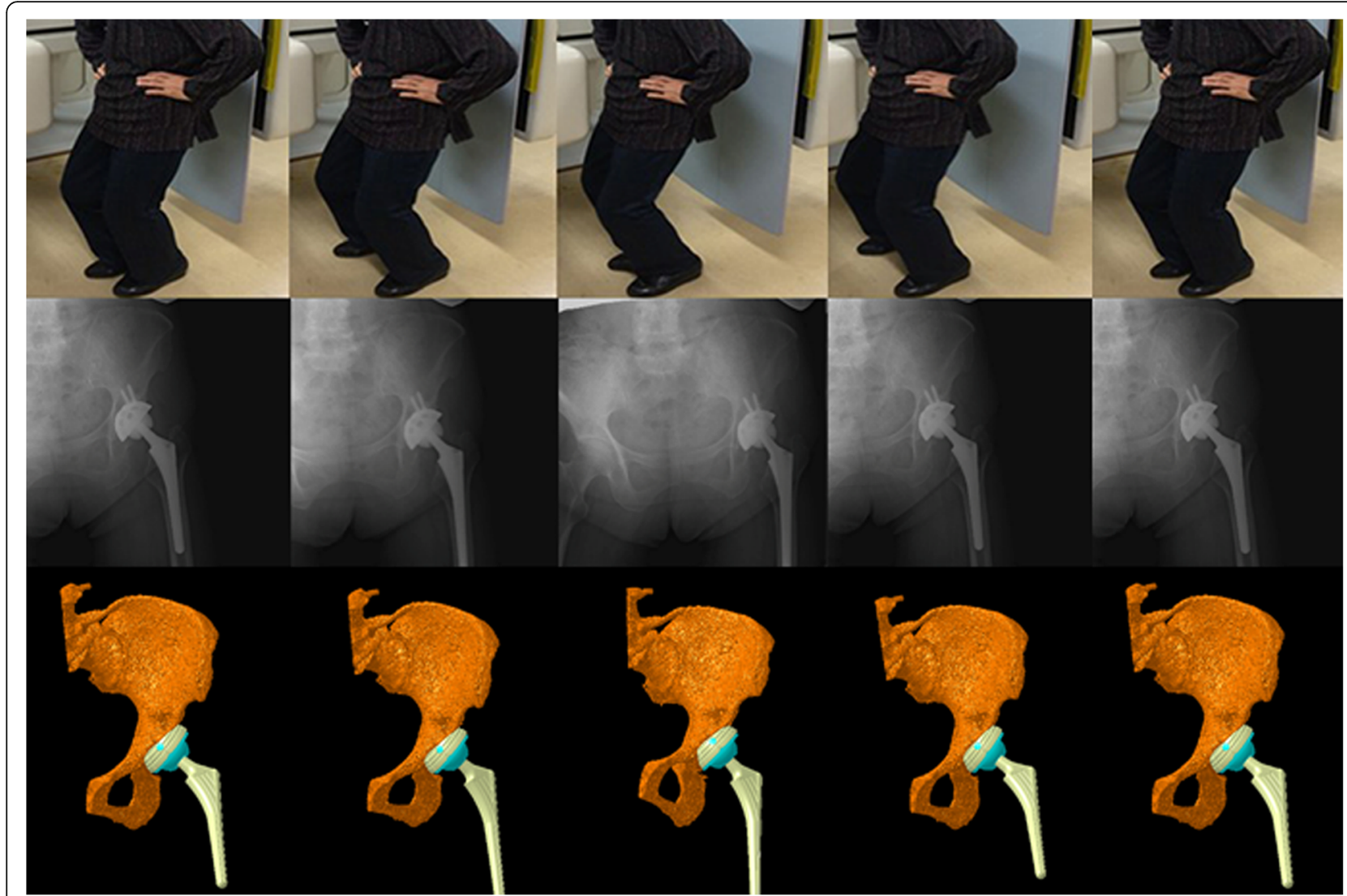

Fig. 4 The hip motions during the hula dance movement kaholo were captured as continuous X-ray images using a flat panel X-ray detector (middle stand) to reconstruct three-dimensional images of the replaced hip joint (lower stand) using image-matching techniques

kinematic patterns of replaced hip joints during dance activities, these kinematic data should be beneficial for advising patients according to the type of physical activity. Motion capture systems with reflective markers have been widely used for in vivo joint kinematics even during classical ballet [22-24]. Quanbeck et al. [22] reported that bilateral hip external rotation during turnout in classical ballet was $49^{\circ}$. Hopper et al. [23] examined hip adduction angle, thigh tilt angle, and knee-hip distance during five ballet movements: rise, relevé, ballonné en place, ballonné traveling, and sissonne. However, external markers attached to the skin might be affected by soft tissue artefacts, producing substantial errors [25-27]. To the best of our knowledge, our case report provides the first kinematic analysis of dance activity in patients after THA using image-matching techniques.
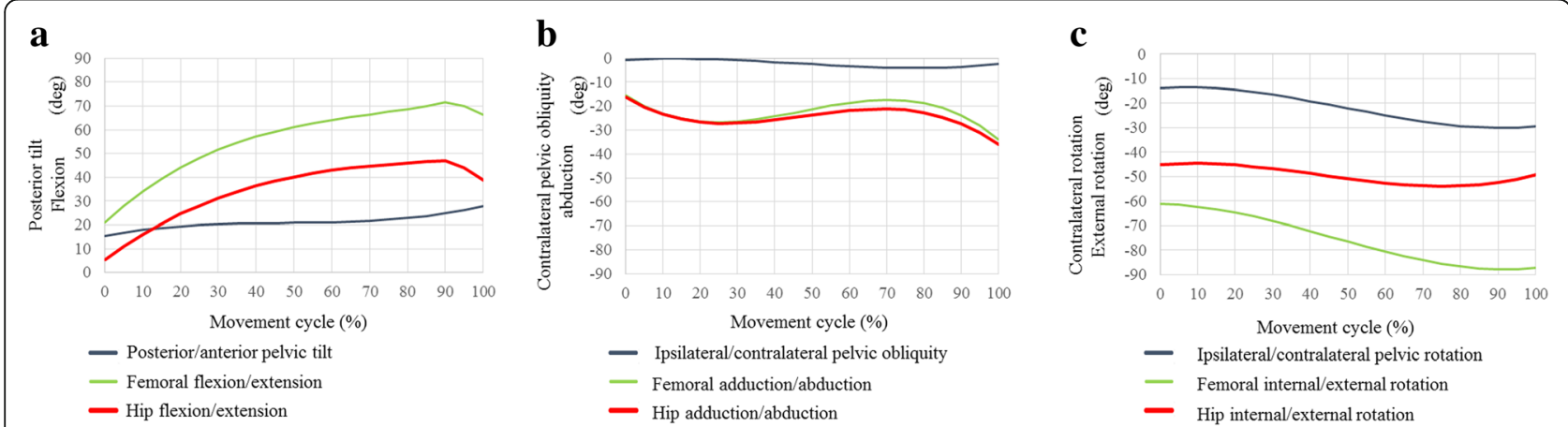

Fig. 5 Posterior/anterior pelvic tilt (posterior + , anterior -), and femoral and hip flexion/extension angles (flexion +, extension -) during développé (a). Ipsilateral/contralateral pelvic obliquity (ipsilateral +, contralateral -), and femoral and hip adduction/abduction angles (adduction +, abduction -) during développé (b). Ipsilateral/contralateral pelvic rotation (ipsilateral +, contralateral -), and femoral and hip internal/external rotation angles (internal +, external -) during développé (c) 

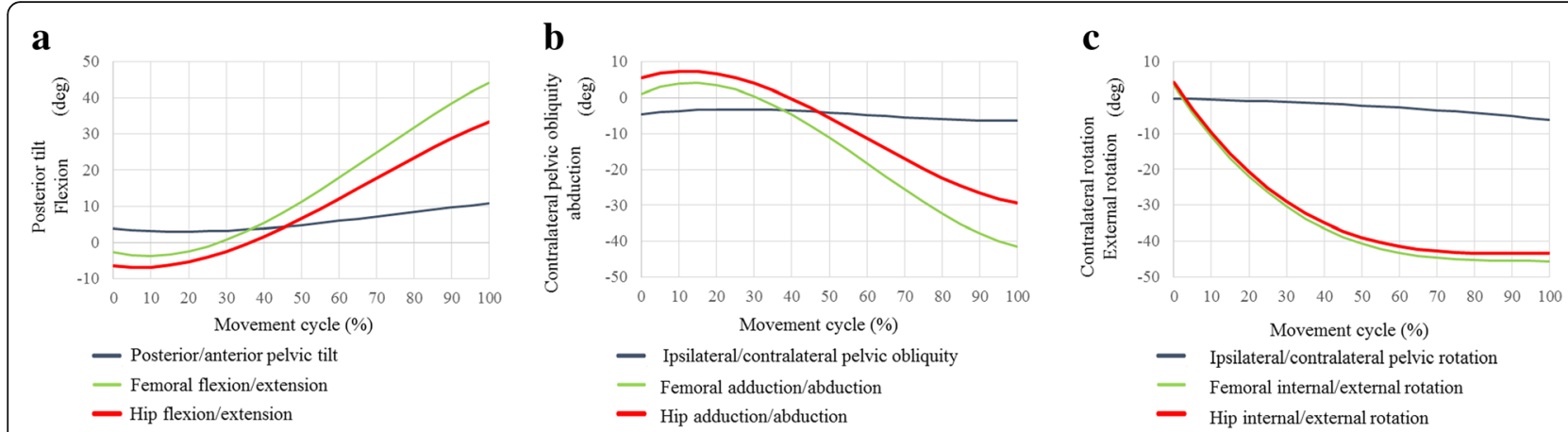

Fig. 6 Posterior/anterior pelvic tilt (posterior +, anterior -), and femoral and hip flexion/extension angles (flexion +, extension -) during plié (a). Ipsilateral/contralateral pelvic obliquity (ipsilateral +, contralateral -), and femoral and hip adduction/abduction angles (adduction +, abduction -) during plié (b). Ipsilateral/contralateral pelvic rotation (ipsilateral +, contralateral -), and femoral and hip internal/external rotation angles (internal +, external -) during plié (c)

Maximum hip flexion of approximately $48^{\circ}$ during développé that we recorded in this study is less than peak hip flexion values of $81^{\circ}$ and $102^{\circ}$ previously reported for chair-rising and squatting in healthy hips [10]. Due to the posterior pelvic tilt, hip flexion/extension showed a lower angle relative to the femoral flexion/ extension, which is consistent with previous kinematic studies [10]. Compared to the développé, smaller hip flexion/extension, adduction/abduction, and internal/external rotation were found during plié. No excessive hip movement or liner-to-neck contact was found during either développé or plié. Specific posture might include potential risks of prosthetic impingement, dislocation, and polyethylene wear [28, 29]. Marchetti et al. [28] examined frequency and risk factors of prosthetic impingement in THA and reported that impingement was found in $51.4 \%$ and was severe in $31.3 \%$. Shon et al. [29] also pointed out that more than half retrieved acetabular components showed impingement. Hara et al. [12] reported that liner-to-neck contact was observed in $36 \%$ of hips without component malpositioning during golf swing.
Hula is the traditional dance of Native Hawaiians, performed by men and women of all ages, and associated with improved physical function, lowering of systemic blood pressure, prevention of cardiac problems, reduced psychological stress, and improved self-regulatory ability [30-32]. Kaholokula et al. reported that movements can vary in intensity and duration, depending on the choreography of the dance, tempo of music, and skill level of the dancer, and can be modified for people with limited physical capacity [30,31]. In terms of hula dance, both kao and kaholo demonstrated small hip flexion/extension, adduction/abduction, and internal/external rotation. No excessive hip movement or liner-to-neck contact was found during either kao or kaholo. No previous report is available of the in vivo three-dimensional kinematics of hula dance even in normal joints. The present study showed that orthopedic surgeons could encourage patients to participate in hula dance and enjoy their active lifestyles after THA.

In our report of two cases, we only evaluated the kinematics of the hip joint during two specific postures in classical ballet and hula dance. Different individuals
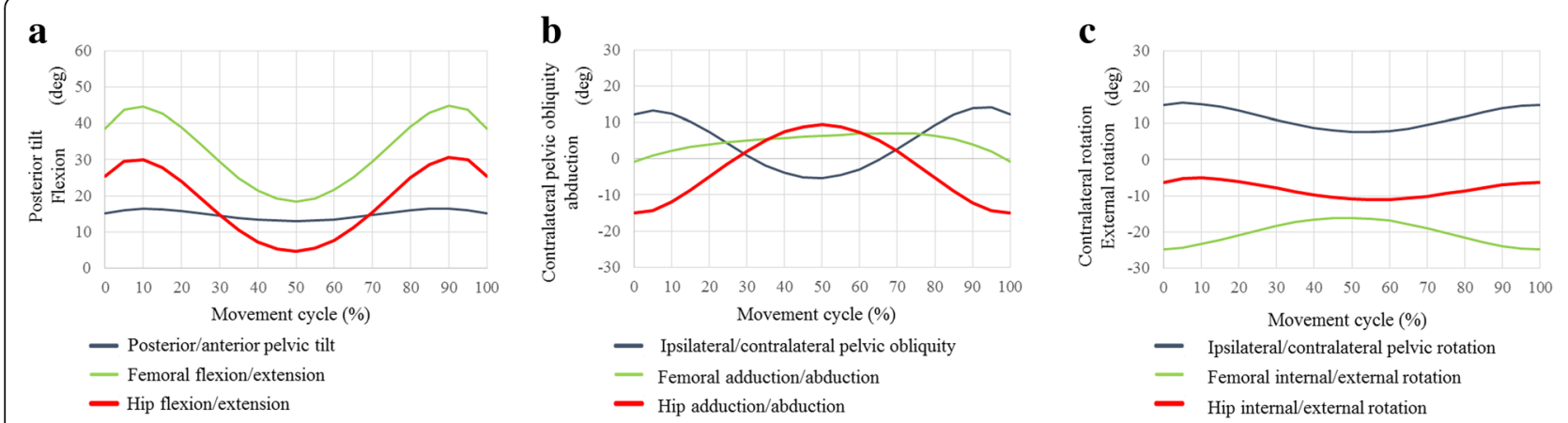

Fig. 7 Posterior/anterior pelvic tilt (posterior + , anterior -), and femoral and hip flexion/extension angles (flexion +, extension -) during kao (a). Ipsilateral/contralateral pelvic obliquity (ipsilateral +, contralateral -), and femoral and hip adduction/abduction angles (adduction +, abduction -) during kao (b). Ipsilateral/contralateral pelvic rotation (ipsilateral +, contralateral -), and femoral and hip internal/external rotation angles (internal +, external -) during kao (c) 

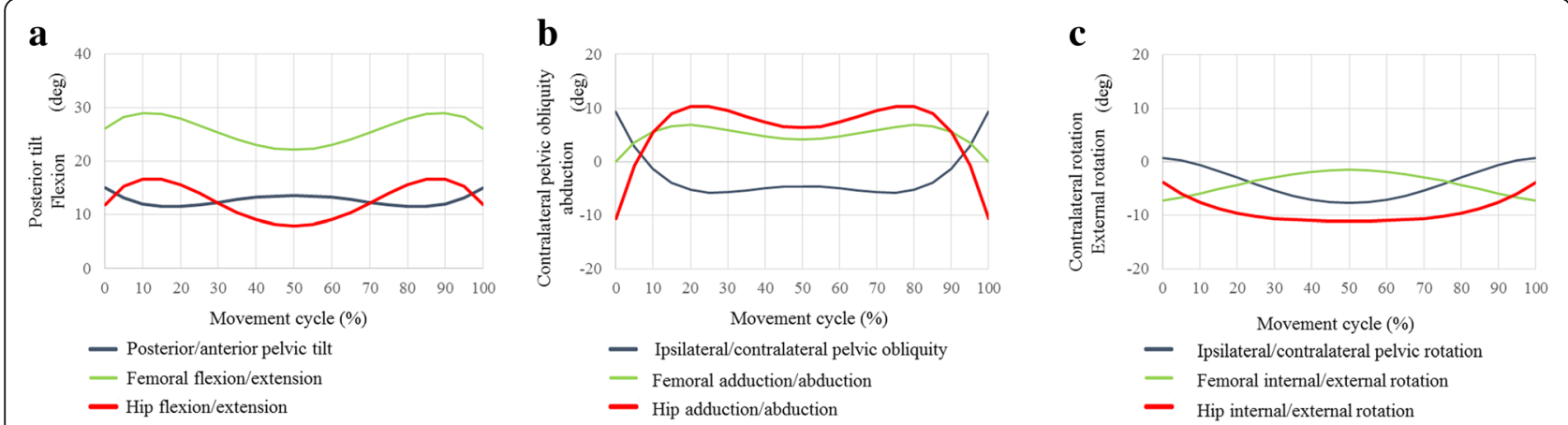

Fig. 8 Posterior/anterior pelvic tilt (posterior +, anterior -), and femoral and hip flexion/extension angles (flexion +, extension -) during kaholo (a). Ipsilateral/contralateral pelvic obliquity (ipsilateral +, contralateral -), and femoral and hip adduction/abduction angles (adduction +, abduction -) during kaholo (b). Ipsilateral/contralateral pelvic rotation (ipsilateral +, contralateral -), and femoral and hip internal/external rotation angles (internal +, external -) during kaholo (c)

would have significant differences between dancing styles, the spine and pelvic mobility, expertise, mood, and so on $[10,33,34]$. Therefore, this study did not clearly demonstrate which styles of dancing could be recommended or may be unsafe in other patients. Further studies with larger cohorts and a control group are desirable to deepen our understanding of the substantial inter-patient variability especially for the personal style of the dancer and skill levels $[10,33,34]$. Although kinematic processing of radiographic measurements is still challenging, time intensive, and requires the risk of radiation exposure, it does represent an important data-driven approach to provide feedback on sports-specific advice for each patient.

\section{Conclusion}

We demonstrated visualization of hip motion during recreational dance activities performed after THA and quantification of the in vivo dynamic kinematics. No excessive, but gradual movements of hip flexion/extension, adduction/abduction, and internal/external rotation were demonstrated during both classical ballet and hula dance. Therefore, dance activities are recommended after THA in these cases. Kinematic data under weight-bearing conditions could be beneficial for advising patients who enjoy their active lifestyles, according to the type of physical activity.

\section{Abbreviations}

CAD: Computer-aided design; CT: Computed tomography; DRRs: Digitally reconstructed radiographs; HHS: Harris Hip Score; OA: Osteoarthritis:

OHS: Oxford Hip Score; ROM: Range of motion; TEA: Transe-epicondylar axis; THA: Total hip arthroplasty; UCLA: University of California-Los Angeles

\section{Acknowledgements}

Not applicable.

\section{Funding}

This work was supported by a Grant-in-Aid for Scientific Research from the Japan Society for the Promotion of Science (No. 25870499).

Availability of data and materials

Not applicable.

\section{Authors' contributions}

$\mathrm{KK}, \mathrm{SH}, \mathrm{DH}, \mathrm{Sl}, \mathrm{HH}$, and $\mathrm{YN}$ contributed to the conception and design of the study; KK and DH performed acquisition of data; $\mathrm{KK}, \mathrm{DH}, \mathrm{SI}, \mathrm{YW}, \mathrm{HG}$, and $\mathrm{HH}$ conducted data analysis; and $\mathrm{DH}, \mathrm{SH}$, and $\mathrm{YN}$ contributed to data interpretation and preparation of the manuscript. All authors approved the final version of the manuscript.

\section{Ethics approval and consent to participate}

All procedures performed in studies involving human participants were in accordance with the ethical standards of our institution and the 1964 Helsinki Declaration and its later amendments or comparable ethical standards.

The patients gave informed consent to participate in this Institutional Review Board (IRB)-approved study (IRB number 24-55) and were informed of the risk of radiation exposure required.

\section{Consent for publication}

Written informed consent was obtained from the patients for publication of this case report and any accompanying images. A copy of the written consents is available for review by the Editor-in-Chief of this journal.

\section{Competing interests}

The authors declare that they have no competing interests.

\section{Publisher's Note}

Springer Nature remains neutral with regard to jurisdictional claims in published maps and institutional affiliations.

\section{Author details}

${ }^{1}$ Department of Orthopedic Surgery, Graduate School of Medical Sciences, Kyushu University, 3-1-1 Maidashi, Higashi-ku, Fukuoka 812-8582, Japan. ${ }^{2}$ Department of Life Science, Faculty of Life Science, Kyushu Sangyo University, 2-3-1 Matsugadai, Higashi-ku, Fukuoka 813-0004, Japan. ${ }^{3}$ Department of Creative Engineering, National Institute of Technology, Kitakyushu College, 5-20-1 Shii, Kokuraminami-ku, Kitakyushu, Fukuoka 802-0985, Japan.

Received: 2 February 2018 Accepted: 5 December 2018

Published online: 12 January 2019

\section{References}

1. Learmonth ID, Young C, Rorabeck C. The operation of the century: total hip replacement. Lancet. 2007;370(9597):1508-19.

2. Nakashima Y, Sato T, Yamamoto T, et al. Results at a minimum of 10 years of follow-up for AMS and PerFix HA-coated cementless total hip arthroplasty: impact of cross-linked polyethylene on implant longevity. J Orthop Sci. 2013;18(6):962-8. 
3. Hamai S, Nakashima Y, Mashima N, et al. Comparison of 10-year clinical wear of annealed and remelted highly cross-linked polyethylene: A propensity-matched cohort study. J Mech Behav Biomed Mater. 2016;59:99-107.

4. Healy WL, Sharma S, Schwartz B, lorio R. Athletic activity after total joint arthroplasty. J Bone and Joint Surg Am. 2008;90(10):2245-52.

5. Ollivier M, Frey S, Parratte S, Flecher X, Argenson JN. Pre-operative function, motivation and duration of symptoms predict sporting participation after total hip replacement. Bone Joint J. 2014;96(8):1041-6.

6. Swanson EA, Schmalzried TP, Dorey FJ. Activity recommendations after total hip and knee arthroplasty. J Arthroplast. 2009;24(6):120-6.

7. Kuster MS. Exercise recommendations after total joint replacement. Sports Med. 2002;32(7):433-45.

8. Lowe CJ, Davies L, Sackley CM, Barker KL. Effectiveness of land-based physiotherapy exercise following hospital discharge following hip arthroplasty for osteoarthritis: an updated systematic review. Physiotherapy. 2015;101(3):252-65.

9. Dubs L, Gschwend N, Munzinger U. Sport after total hip arthroplasty. Arch Orthop Trauma Surg. 1983;101(3):161-9.

10. Hara D, Nakashima Y, Hamai $S$, et al. Kinematic Analysis of Healthy Hips during Weight-Bearing Activities by 3D-to-2D Model-to-Image Registration Technique. Biomed Res Int. 2014; https://doi.org/10.1155/2014/457573

11. Hara D, Nakashima Y, Hamai S, et al. Dynamic hip kinematics in patients with hip osteoarthritis during weight-bearing activities. Clin Biomech. 2016; 32:150-6.

12. Hara D, Nakashima Y, Hamai S, et al. Dynamic Hip Kinematics During Golf Swing In Patients After Total Hip Arthroplasty. Am J Sports Med. 2016;44:1801-9.

13. Yoshimoto K, Hamai S, Higaki H, Gondoh T, Nakashima Y. Visualization of cam-type femoroacetabular impingement during squatting using imagematching techniques: a case report. Skelet Radiol. 2017;46(9):1277-82.

14. Koyanagi J, Sakai T, Yamazaki T, et al. In vivo kinematic analysis of squatting after total hip arthroplasty. Clin Biomech. 2011;26:477-83.

15. Tsai T-Y, Li J-S, Wang S, et al. A novel dual fluoroscopic imaging method for determination of THA kinematics: In-vitro and in-vivo study. J Biomech. 2013; 46:1300-4.

16. Uesugi Y, Makimoto K, Fujita K, Nishii T, Sakai T, Sugano N. Validity and responsiveness of the Oxford hip score in a prospective study with Japanese total hip arthroplasty patients. J Orthop Sci. 2009;14:35-9.

17. Naal FD, Impellizzeri FM, von Eisenhart-Rothe R, Mannion AF, Leunig M. Reproducibility, validity, and responsiveness of the hip outcome score in patients with end-stage hip osteoarthritis. Arthritis Care Res. 2012;64:1770-5.

18. Amstutz HC, Thomas BJ, Jinnah R, Kim W, Grogan T, Yale C. Treatment of primary osteoarthritis of the hip. A comparison of total joint and surface replacement arthroplasty. J Bone Joint Surg Am. 1984;66:228-41.

19. Harris WH. Traumatic arthritis of the hip after dislocation and acetabular fractures: treatment by mold arthroplasty. An end-result study using a new method of result evaluation. J Bone Joint Surg Am. 1969;51:737-55.

20. Murray DW. The definition and measurement of acetabular orientation. Bone Joint Surg Br. 1993;75(2):228-32

21. Nakashima $Y$, Hirata M, Akiyama $M$, et al. Combined anteversion technique reduced the dislocation in cementless total hip arthroplasty. Int Orthop. 2014;38(1):27-32.

22. Quanbeck AE, Russell JA, Handiey SC, Quanbeck DS. Kinematic analysis of hip and knee rotation and other contributors to ballet turnout. J Sports Sci. 2007:35(4):331-8.

23. Hopper LS, Sato N, Weidemann AL. Single-leg squats can predict leg alignment in dancers performing ballet movements in "turnout". Open Access J Sports Med. 2016;16(7):161-6.

24. Imura A, lino Y, Kojima T. Kinematic and kinetic analysis of the fouetté turn in classical ballet. J Appl Biomech. 2010;26(4):484-92.

25. Cappozzo A, Catani F, Croce UD, Leardini A. Position and orientation in space of bones during movement: anatomical frame definition and determination. Clin Biomech (Bristol, Avon). 1995;10(4):171-8.

26. Reinschmidt C, van den Bogert AJ, Nigg BM, Lundberg A, Murphy N. Effect of skin movement on the analysis of skeletal knee joint motion during running. J Biomech. 1997;30(7):729-32.

27. McGinley $J$, Baker $R$, Wolfe $R$, Morris ME. The reliability of three-dimensional kinematic gait measurements: a systematic review. Gait Posture. 2009:29(3):360-9.

28. Marchetti E, Krantz N, Berton C, Bocquet D, Fouilleron N, Migaud H, Girard J. Component impingement in total hip arthroplasty: frequency and risk factors. A continuous retrieval analysis series of 416 cup. Orthop Traumatol Surg Res. 2011;97(2):127-33.
29. Shon WY, Baldini T, Peterson MG, Wright TM, Salvati EA. Impingement in total hip arthroplasty a study of retrieved acetabular components. J Arthroplasty. 2005;20(4):427-35

30. Kaholokula JK, Look MA, Wills TA, et al. Kā-HOLO Project: a protocol for a randomized controlled trial of a native cultural dance program for cardiovascular disease prevention in Native Hawaiians. BMC Public Health. 2017;17(1):321.

31. Kaholokula JK, Look M, Mabellos T, et al. Cultural Dance Program Improves Hypertension Management for Native Hawaiians and Pacific Islanders: a Pilot Randomized Trial. J Racial Ethn Health Disparities. 2017;4(1):35-46.

32. Maskarinec GG, Look M, Tolentino K, Trask-Batti M, Seto T, de Silva M, Kaholokula JK. Patient perspectives on the Hula Empowering Lifestyle Adaptation Study: benefits of dancing hula for cardiac rehabilitation. Health Promot Pract. 2015;16(1):109-14.

33. Hemmerich A, Brown H, Smith S, Marthandam SS, Wyss UP. Hip, knee, and ankle kinematics of high range of motion activities of daily living. J Orthop Res. 2006;24(4):770-81.

34. Kolo FC, Charbonnier C, Pfirrmann CW, et al. Extreme hip motion in professional ballet dancers: dynamic and morphological evaluation based on magnetic resonance imaging. Skelet Radiol. 2013;42(5):689-98.

\section{Ready to submit your research? Choose BMC and benefit from:}

- fast, convenient online submission

- thorough peer review by experienced researchers in your field

- rapid publication on acceptance

- support for research data, including large and complex data types

- gold Open Access which fosters wider collaboration and increased citations

- maximum visibility for your research: over $100 \mathrm{M}$ website views per year

At BMC, research is always in progress.

Learn more biomedcentral.com/submissions 